\title{
A Case Report of Unilateral Pediatric Cataract Surgery: Posterior Capsule Opacification and Visual Rehabilitation
}

\author{
Dian Estu Yulia ${ }^{1}$, Ferdinand Inno Luminta ${ }^{1}$ \\ ${ }^{1}$ Department of Ophthalmology, Faculty of Medicine, University of Indonesia, \\ Dr. Cipto Mangunkusumo Hospital Jakarta \\ E-mail: dianestu.dianestu@gmail.com
}

\begin{abstract}
Objective: To report a case of posterior capsule opacification (PCO) and severe deprivation amblyopia following unilateral pediatric cataract surgery

Case Presentation: A 4-year-old girl presented with PCO of the right eye with a history of unilateral congenital cataract surgery and intraocular lens (IOL) implantation without optimal visual rehabilitation two years ago at another hospital in Jakarta. Her uncorrected right eye visual acuity was $3 / 60$ and corrected left eye visual acuity 6/7.5. We performed secondary posterior capsulotomy and anterior vitrectomy of the right eye. Following the procedure, the patient did not regain her vision despite normal posterior segment; thus, a diagnosis of deprivation amblyopia was made. She was prescribed occlusion therapy for 6 hours a day on the left eye to decrease the degree of amblyopia of her right eye.

Conclusion: Early identification and management of pediatric cataract surgery complications combined with optimal visual rehabilitation may benefit the patient in the long run. If not treated properly, especially in unilateral cataract cases, it may be too late to regain visual function.
\end{abstract}

Keywords: posterior capsule opacification, deprivation amblyopia, pediatric cataract

\section{INTRODUCTION}

$\mathrm{E}$ arly detection and treatment of detection and treatment of pediatric cataracts are vital to gain good visual outcomes. Pediatric cataract surgery outcome depends on several factors. Postsurgical events after pediatric cataract surgery such as visual rehabilitation and posterior capsule opacification (PCO) are still much discussed compared to the adult. ${ }^{1}$ Some studies stated that PCO almost certainly happens in children who underwent cataract surgery, in which $39 \%$ to $100 \%$ of those will happen to them whose posterior capsule was left intact. ${ }^{2,3}$ Primary posterior capsulotomy and anterior vitrectomy during pediatric cataract surgery are effective in preventing PCO. ${ }^{4}$ It is crucial to treat $\mathrm{PCO}$ in children since it is more visually threatening as an amblyogenic factor and has a quicker onset than adults. Furthermore, the risk of deprivation amblyopia is higher in unilateral cases. The timing of surgery is more critical in unilateral cases of pediatric cataracts. This condition is worsened because even after the cataract is removed, PCO may develop, thus making the risk factor for deprivation amblyopia greater. ${ }^{5,6}$ 


\section{CASE ILUSTRATION}

A 4-year-old girl was brought to the hospital with a chief complaint of her right eye's blurred vision. The patient had undergone cataract surgery of her right eye when she was two years old at a private hospital. At first, her mother noticed that her right eye often moves inward, and it was revealed that the patient had a unilateral cataract on her right eye. She underwent cataract surgery and was told to do occlusion therapy after the surgery, but the caregiver's compliance was low. The patient was then told that she had a secondary cataract following cataract surgery and then referred to Cipto Mangunkusumo Hospital. Ophthalmological examination revealed that the patient had $30^{\circ}$ esotropia on the right eye. [Figure 1] The visual acuity was $3 / 60$ not corrected with a pinhole on the right eye and for the left eye was 6/7.5 with correction. Intraocular pressures were within normal limits in both eyes. The corneal diameter of the right eye was $12 \mathrm{~mm}$ and the iris/pupil was irregular with posterior synechiae and peripheral iridectomy. There was an intraocular lens (IOL) with PCO and Visual Axis Opacity (VAO). Posterior segment was within normal limit with ultrasonography examination.

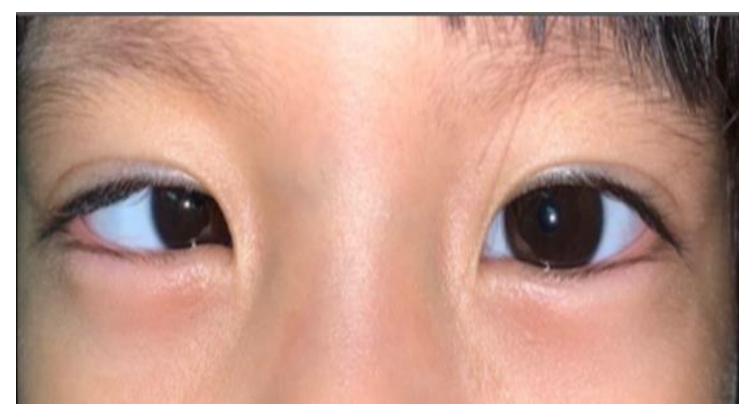

Fig 1. Initial examination showed $30^{\circ}$ esotropia of the right eye

The patient underwent surgery for clearing visual axis, including secondary posterior capsulotomy, synechiolysis, anterior vitrectomy, and irrigation aspiration of the remaining lens mass. [Figure 2] One-month following the procedure, the right eye's visual acuity was
2/60. Best Corrected Visual Acuity (BCVA) measured with Snellen chart was 6/60 using S-4.50 C-1.50 X 160. Meanwhile, the left eye BCVA was $6 / 7.5$ using S+3.00 C-2.00 x 15. There was still sensory esotropia on the right eye. The anterior segment of the right eye showed an irregular pupil with IOL and a clear visual axis. The posterior segment was still within the normal limit with an indirect fundoscopy examination. The patient was prescribed glasses and instructed to do occlusion therapy for 6 hours a day to improve the amblyopia, patient was followed up every 3 months to evaluate improvement in visual acuity with a target of having the left visual acuity be comparable to the right eye.

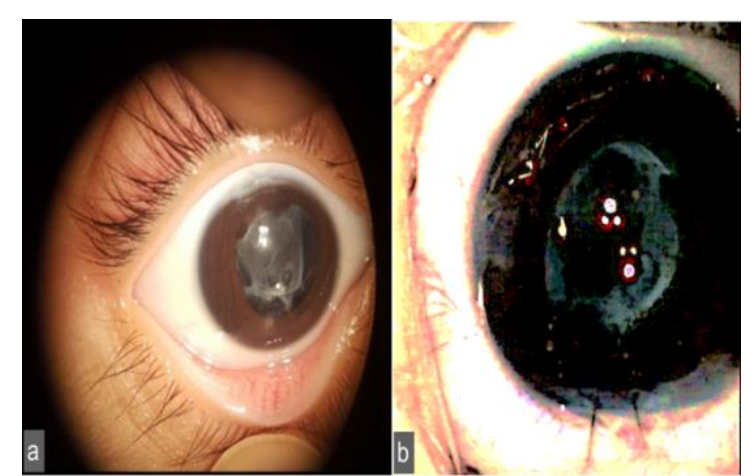

Fig 2. (a) Posterior capsular opacification developed after cataract surgery of the right eye; (b) Post-secondary capsulotomy result (intraoperatively)

\section{DISCUSSION}

Visual result following pediatric cataract surgery are often more unsatisfactory than adult due to several reasons such as amblyopia, which develops in pediatric cataract, and higher rate of complication. ${ }^{7}$ One of the most common complication is PCO. This complication interferes the main goal of the procedure which is to clear and provide the optical correction on the visual axis. Several factors affect the prevalence of PCO following pediatric cataract surgery, including the age of the patient at the time of surgery, comorbidities of ocular pathologies, surgical procedures, lens status (aphakia or pseudophakia), IOL type (material and 
designs), sulcus or capsular bag fixation (site of fixation), and surgical trauma. ${ }^{1,7}$

This patient was found to have a more fibrous type of PCO in which LEC (lens epithelial cell) undergo proliferation resulting in fibrous metaplasia. This condition might produce folds and wrinkle on posterior capsules causing significant visual loss. Our patient was also two years old when she underwent pediatric cataract surgery and had PCO when she was four years old. The mean time for age at PCO occurrence is varied in literature, ranging from 1 to 26 months. Some reported that 18 months is the peak of PCO appearance. ${ }^{8}$ Other studies were found that the younger the age of surgery, the more likely PCO develops. ${ }^{9,10}$ It may be due to more severe postoperative inflammation in younger children. However, Perseim and Wilson et al. found that the opacification occurred less frequent in older children $(>2$ months old). ${ }^{11}$

The management of PCO significantly contributes to the outcome of pediatric cataract surgery. Posterior capsulotomy, combined and anterior vitrectomy, is considered the gold standard of pediatric cataract surgery. These procedures are recommended for those children up to nine years old, specifically for those under the age of seven because the opacification risk is higher, and amblyopia may happen. ${ }^{1,7}$ We did not have information about the procedures of the previous cataract surgery that had been done in our patient regarding whether the posterior capsulotomy and anterior vitrectomy was performed or not.

Another factor to consider is fellow eye's status; patients with bilateral cataract are not subjects to anisometropia, making it justifiable to leave them with more significant initial hyperopia compared to children with unilateral cataract. It is better to leave less refractive error if the child and family are expected to comply poorly with glasses, contact lens, or occlusion therapy. Enyedi et al. ${ }^{12}$, Plager et al. ${ }^{13}$, and Trivedi and Wilson had different postoperative refractive goals for children based on their age at surgery. ${ }^{7}$ (Table 1) Although the IOL power, type, and refractive target data are not available for the time during the patient's follow up in our hospital; the refractive status was $\mathrm{S}-4.50$ for her right eye, which we suspect the previous surgeon might aim for emmetropia status rather than under correction.

Table 1. Recommendation of postoperative refractive goals for children aged 1 to 8 years ${ }^{7,12,13}$

\begin{tabular}{|c|c|c|c|}
\hline \multirow{2}{*}{$\begin{array}{c}\text { Age at } \\
\text { surgery } \\
\text { (year) }\end{array}$} & \multicolumn{3}{|c|}{ Postoperative Goal (D) } \\
\cline { 2 - 4 } & Enyedi et al. & Plager et al. & $\begin{array}{c}\text { Trivedi and } \\
\text { Wilson }\end{array}$ \\
\hline $\mathbf{1}$ & +6 & & +6 \\
\hline $\mathbf{2}$ & +5 & & +5 \\
\hline $\mathbf{3}$ & +4 & +5 & \\
\hline $\mathbf{4}$ & +3 & +4 & +4 \\
\hline $\mathbf{5}$ & +2 & +3 & +3 \\
\hline $\mathbf{6}$ & +1 & +2.25 & +2 \\
\hline $\mathbf{7}$ & 0 & +1.5 & +1.5 \\
\hline $\mathbf{8}$ & -1 to -2 & +1 & +1 \\
\hline $\mathbf{1 0}$ & & & +0.5 \\
\hline$>\mathbf{1 4}$ & & & 0 \\
\hline
\end{tabular}

Unilateral cataract is the most common cause of deprivation amblyopia, and it is the most refractory to the treatment. The main principle of gaining the best visual outcome in unilateral cataract is early cataract removal. Evidence showed that the cutoff point for an optimal visual outcome is between six to ten weeks at most. ${ }^{14}$ Studies found that visual outcome is worse in a unilateral cataract than bilateral cataracts, in which out of 74 cases of unilateral cataracts, only $37 \%$ had a final acuity of $20 / 40$ or better. ${ }^{15}$ Our patient underwent unilateral cataract surgery when she was two years, and it is worsened by that she developed PCO, making it a higher risk for deprivation amblyopia.

Occlusion therapy for the better eye remained to be the primary therapy for deprivation amblyopia. 6,15 Several studies suggested that occlusion therapy ranges from 6 to 8 and 8 to 10 hours per day. ${ }^{9}$ The hours of occlusion can be reduced as the patient gets older. Compliance is one of the challenges in occlusion therapy. Studies have reported that $31 \%$ of unilateral 
cataracts have stopped doing occlusion by the age of $4 .{ }^{16}$

The patient also had had sensory esotropia before the surgery. Merino et al. ${ }^{6}$ showed that sensorial strabismus found in congenital cataract for $72.4 \%$ and unilateral cataract had more predisposition to strabismus, especially in esotropia. ${ }^{6}$ Furthermore, a study by Birch et al. showed that the prolonged duration of the cataract (>6 weeks) was associated with a higher risk for strabismus and nystagmus (OR 9.2 and 46.2, respectively). Since the patient had pediatric cataract surgery when she was two years old, it might increase the risk of having esotropia. Strabismus with unilateral cataract is considered to be an absolute indication for cataract surgery. ${ }^{17}$

\section{CONCLUSION}

Posterior capsule opacification (PCO) is one of the most common complications following pediatric cataract surgery. This study highlights the importance of unilateral cataract giving a higher risk of deprivation amblyopia for the patient. Furthermore, favorable surgical outcomes depend on timely surgery for the unilateral cataract and unilateral PCO for this case. If not done promptly and correctly, it might lead to another complication which is strabismus (esotropia). Visual rehabilitation following the surgery is also essential to achieve the best visual acuity for the patient.

\section{REFERENCES}

1. Vasavada AR, Praveen MR, Tassignon M-J, Shah SK, Vasavada VA, Vasavada VA, et al. Posterior capsule management in congenital cataract surgery. J Cataract Refract Surg. 2011;37(1):173-93.

2. Atkinson CS, Hiles DA. Treatment of secondary posterior capsular membranes with the Nd:YAG laser in a pediatric population. Am J Ophthalmol. 1994;118(4):496-501.

3. Lambert SR, Drack A V. Infantile cataracts. Surv Ophthalmol. 1996;40(6):427-58.

4. Kugelberg M, Zetterström C. Pediatric cataract surgery with or without anterior vitrectomy. J Cataract Refract Surg. 2002;28(10):1770-3.

5. Birch EE, Cheng C, Stager DRJ, Weakley
DRJ, Stager DRS. The critical period for surgical treatment of dense congenital bilateral cataracts. J AAPOS Off Publ Am Assoc Pediatr Ophthalmol Strabismus. 2009;13(1):67-71.

6. Merino P, Gómez-de-Liaño P, Gil MR, Fernández AI, Yáñez J, Cortés C. Strabismus and congenital cataracts. Arch Soc Esp Oftalmol. 2007;82(10):623-8.

7. Vasavada AR, Nihalani BR. Pediatric cataract surgery. Curr Opin Ophthalmol. 2006;17(1):54-61.

8. Jensen AA, Basti S, Greenwald MJ, Mets MB When may the posterior capsule be preserved in pediatric intraocular lens surgery? Ophthalmology. $\quad 2002 ; 109(2): 324-7$; discussion 328.

9. Hosal BM, Biglan AW. Risk factors for secondary membrane formation after removal of pediatric cataract. J Cataract Refract Surg. 2002;28(2):302-9.

10. Sinha R, Shekhar H, Sharma N, Titiyal J, Vajpayee R. Posterior capsular opacification: A review. Indian J Ophthalmol. :371 OP-376 VO-61.

11. Peterseim MW, Wilson ME. Bilateral intraocular lens implantation in the pediatric population. Ophthalmology. 2000;107(7):1261-6.

12. Enyedi LB, Peterseim MW, Freedman SF, Buckley EG. Refractive changes after pediatric intraocular lens implantation. Am J Ophthalmol. 1998;126(6):772-81.

13. Plager DA, Kipfer H, Sprunger DT, Sondhi N, Neely DE. Refractive change in pediatric pseudophakia: 6-year follow-up. J Cataract Refract Surg. 2002;28(5):810-5.

14. Pehere NK, Chandrasekhar G, Kekunnaya R. The critical period for surgical treatment of dense congenital bilateral cataracts. J AAPOS. 2009;13(5):527-8.

15. Hosal BM, Biglan AW, Elhan AH. High levels of binocular function are achievable after removal of monocular cataracts in children before 8 years of age. Ophthalmology. 2000;107(9):1647-55.

16. Allen RJ, Speedwell L, Russell-Eggitt I. Longterm visual outcome after extraction of unilateral congenital cataracts. Eye (Lond). 2010;24(7):1263-7.

17. Wilson ME. Pediatric Cataracts: Overview. American Academy of Ophthalmology [Internet]. 2015. Available from: https://www.aao.org/diseasereview/pediatric-cataracts-overview 